\title{
MICROSTRUCTURE AND TEXTURE DEVELOPMENT IN BORON DOPED $\mathrm{Ni}_{3} \mathrm{Al}$
}

\author{
J. Ball, B. Zeumer, and G. Gottstein \\ Institut für Metallkunde und Metallphysik, RWTH Aachen, \\ Kopernikusstr. 14, D-5100 Aachen, FRG
}

\section{INTROCUCTION}

The current study addresses the microstructural evolution and texture development of two ductilized nickel-aluminides, namely single phase boron-doped $\mathrm{Ni}_{76} \mathrm{Al}_{24}$ (ICl5) and two-phase boron-doped $\mathrm{Ni}_{27} \mathrm{Al}_{21}+\mathrm{Zr} / \mathrm{Fe}$ (IC50). These intermetallic compounds have potential for high temperature structural applications, but can be processed by conventional forming and recrystallization treatment. Despite the worldwide interest in this material and extensive research efforts on its mechanical properties, there are virtually no systematic studies of microstructure and texture development of this class of material.

\section{EXPERIMENTAL PROCEDURES}

The two different nickel-aluminides under investigation had the composition $\mathrm{Ni}_{76} \mathrm{Al}_{24}+0.24 \mathrm{at} \% \mathrm{~B}$ (IC15) and $\mathrm{Ni}_{7} \mathrm{Al}_{21}+0.2 \mathrm{at} \% \mathrm{~B}+0.49 \mathrm{at} \% \mathrm{Zr}+$ $0.42 \mathrm{at} \% \mathrm{Fe}$ (IC50), respectively. The latter was provided by Allegheny Ludlum Steel, USA, in form of a cast sheet of $1.3 \mathrm{~mm}$ thickness. Two different initial microstructures of IC15 were investigated. One sample was cut from the as-cast ingot of IC15 which has a large grain size and remnants of a second phase. A second sample was produced by uniaxially forging of the cast ingot by $35 \%$ and recrystallization to yield a homogeneous grain size of about $60 \mu \mathrm{m}$.

These materials were subjected to microstructural investigations and texture measurements at rolling reductions between $50 \%$ and $95 \%$. The recrystallization textures were measured for IC15, cold rolled to $92 \% / 90 \%$ and annealed for $1 \mathrm{~h} / 90 \mathrm{~min}$ at $750^{\circ} \mathrm{C} / 710^{\circ} \mathrm{C}$, respectively and for IC50, cold rolled to $90 \%$ and annealed for $90 \mathrm{~min}$ at $850^{\circ} \mathrm{C}$. Invariably the textures were determined in the center section of the sample.

\section{EXPERIMENTAL RESULTS}

The microstructural development of IC15 by cold rolling (Fig.1) is 
characterized by progressively heavy shear band formation across grains which is obvious already at $70 \%$ rolling reduction. The vastly different initial microstructures of the IC15 evidently affect the microstructural evolution during rolling. The coarse grained initial microstructure exhibits much heavier shear band formation. The inclination of the shear bands to the rolling plane is in the order of $24^{\circ}$ to $35^{\circ}$. The microstructure of the homogenized IC50 (Fig.2) is a duplex microstructure of $\gamma / \gamma^{\prime}$ phases in agreement with the phase diagram. The columnar shape of the grains is due to the solidification of the thin sheet. At a higher magnification (Fig.3) the precipitation of small $\gamma^{\prime}$ particles inside the $\gamma$ phase is visible in analogy to the well-known superalloys.
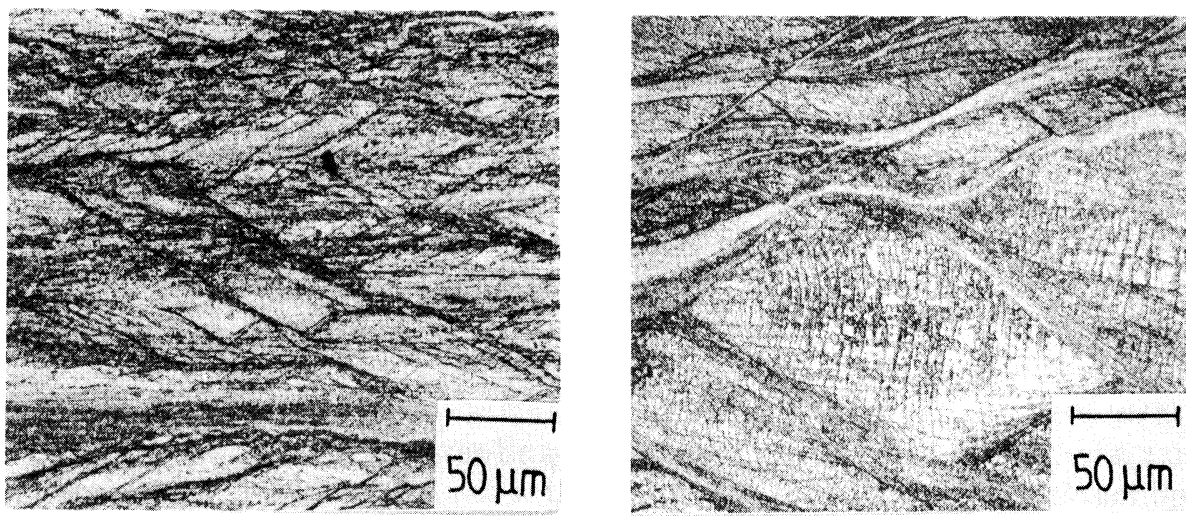

Fig.1 Microstructure of (a) $90 \%$ and (b) $70 \%$ cold rolled IC15 with a large and a small grain size, respectively

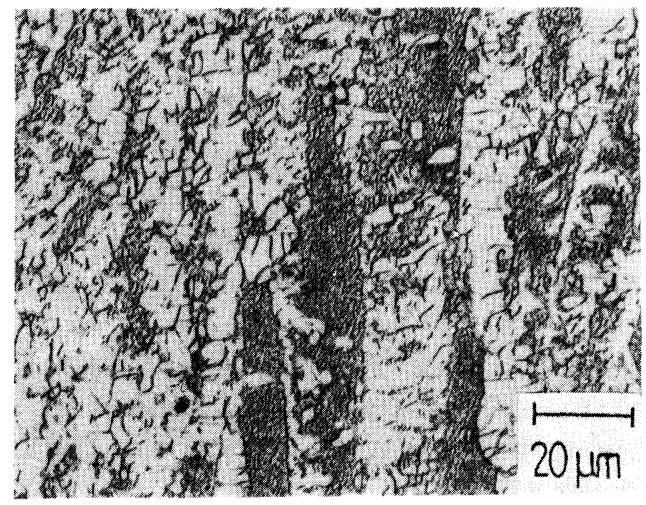

Fig. 2 Microstructure of IC50 after homogenization for $3 \mathrm{~h}$ at $1050^{\circ} \mathrm{C}$

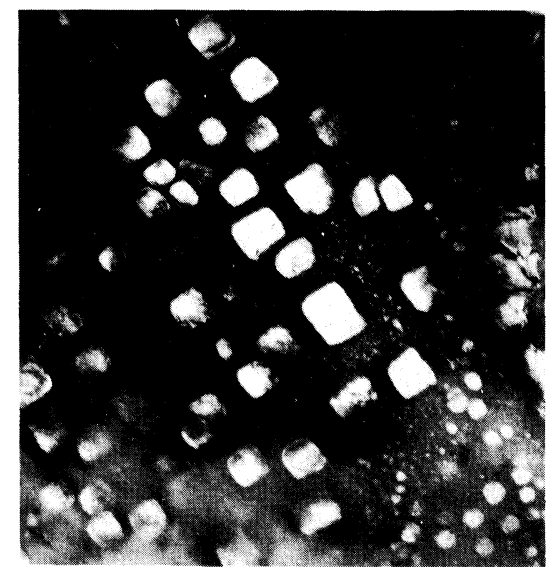

Fig.3 TEM micrograph of IC50, 50K

The recrystallization kinetics were obtained by microhardness measurements during isochronal annealing (Fig.4). The two alloys show distinctly different sof tening behavior. For IC 15 the drop in hardness at 
about $650^{\circ} \mathrm{C}$ could be related to recrystallization without measurable prior recovery. The alloy IC50 shows a slight increase in hardness at moderate annealing temperatures most likely due to phase transformations, then it reveals softening before recrystallization starts at about $750^{\circ} \mathrm{C}$. At still higher annealing temperatures the hardness continues to drop even more quickly for IC15 due to grain growth, which obviously contributes considerably to the loss of strength. In contrast, for IC50 the curve exhibits a plateau in hardness above $900^{\circ} \mathrm{C}$.

The rolling textures develop rapidly and the final texture is essentially established already after $60 \%$ rolling. Higher degrees of rolling only sharpen the texture. The fine and coarse grained IC15 exhibit quite different rolling texture evolu- (b)

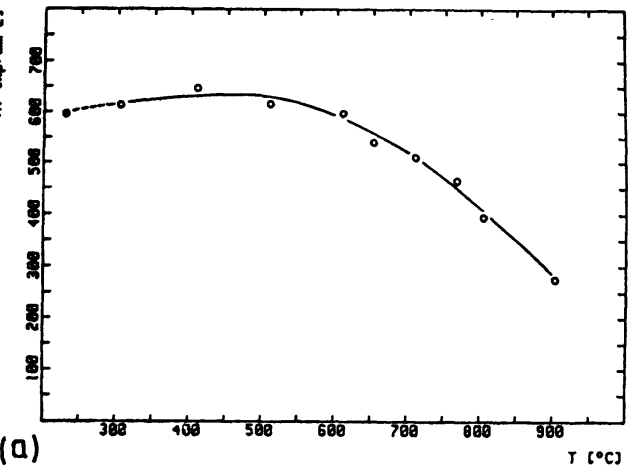
tion. While the fine grained material develops a typical Cu-type texture Fig.4 Microhardness vs. temperature (Fig.5), a brass-type texture was for isochronal annealing of $85 \%$ cold found in the coarse grained material rolled (a) IC15 and (b) IC50

(Fig.6). The IC50 specimen also shows essentially a $\mathrm{Cu}$-type rolling texture (Fig.7) but much less pronounced than the fine grained IC15. A texture analysis with regard to its main components reveals in comparison to disordered alloys an unusually high background (in the order of $60 \%$ ) even for the most distinct rolling texture in IC15 (Fig.8a). The distribution of volume fractions substantiates the $S$-orientation $\{123\}<634>$ as the strongest component and weaker $C\{112\}<111>$ and $B\{110\}<112>$ components, but the $B-$ orientation becomes significantly stronger at high rolling degrees (Fig.8b). This is evident also from the development of orientation densities along the $\alpha$ - and $\beta$-fibers (Fig.9).

Despite apparently different rolling textures, the recrystallization textures of the two IC15 grades are very similar (Fig.10a,b). The main recrystallization components are approximately $\{012\}<121>$ and $\{112\}<131>$. However, the recrystallization textures are very weak with the intensities of even these major components being extremely low, since the background amounts to approximately $90 \%$. The recrystallized IC50 specimen had a different recrystallization texture (Fig.10c). While the $\{012\}<121>$ component 


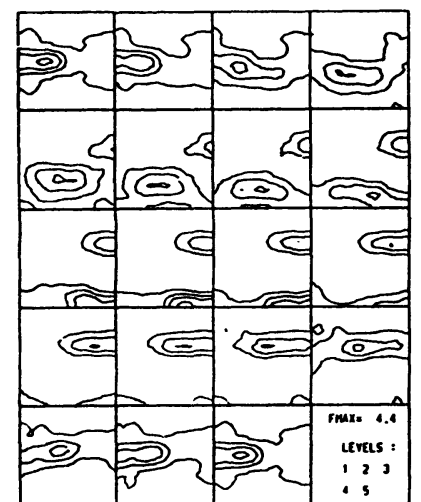

(a)

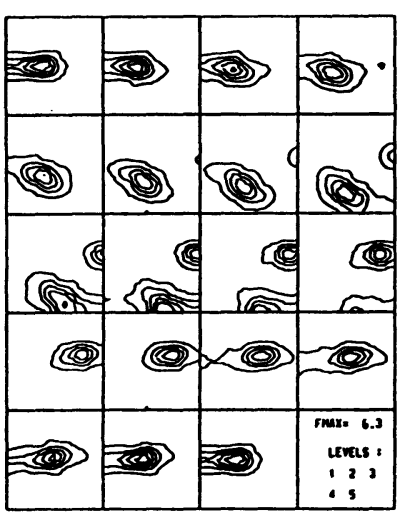

(b)

Fig.5 Compl. ODF ( $\varphi_{2}=$ const) for (a) $61 \%$ and (b) $92 \%$ cold rolled IC 15

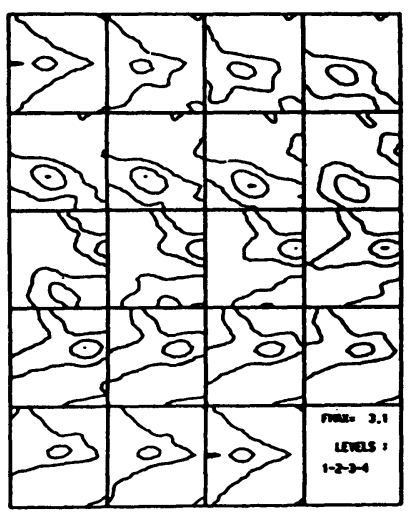

Fig.7 Exp. ODF ( $\varphi_{2}=$ const) for $90 \%$ cold rolled IC 50

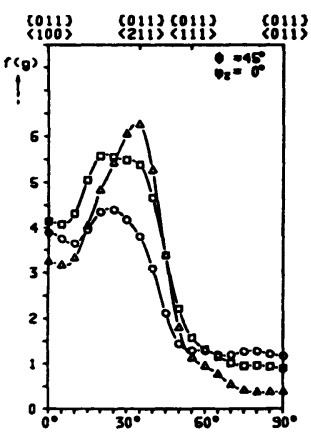

(a)

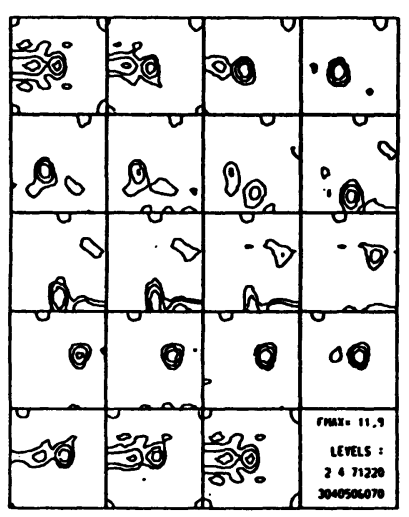

Fig.6 Compl. ODF ( $\varphi_{2}=$ const) for $90 \%$ cold rolled IC15 with a large grain size

Fig.9 Orientation density $f(g)$ along (a) the $\alpha$-fiber and (b) the $\beta$-fiber

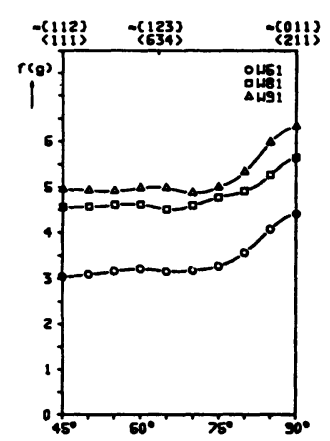

(b)

\section{(n)}

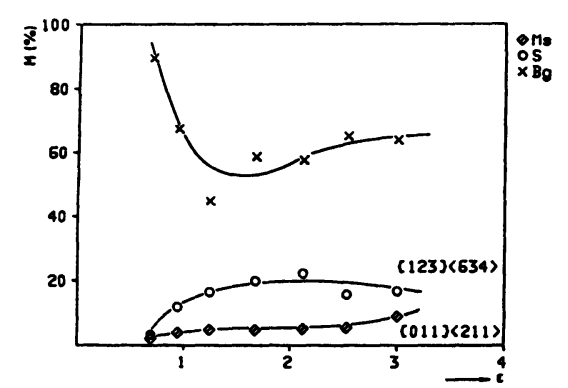

(a)

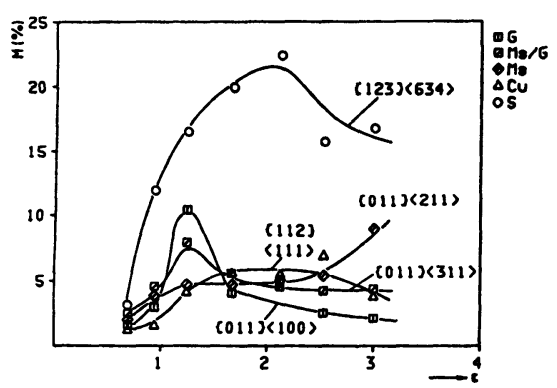

(b)

Figure 8 Volume fractions of the main rolling texture components, (a) including background (Bg): (b) magnified scale including minor components 

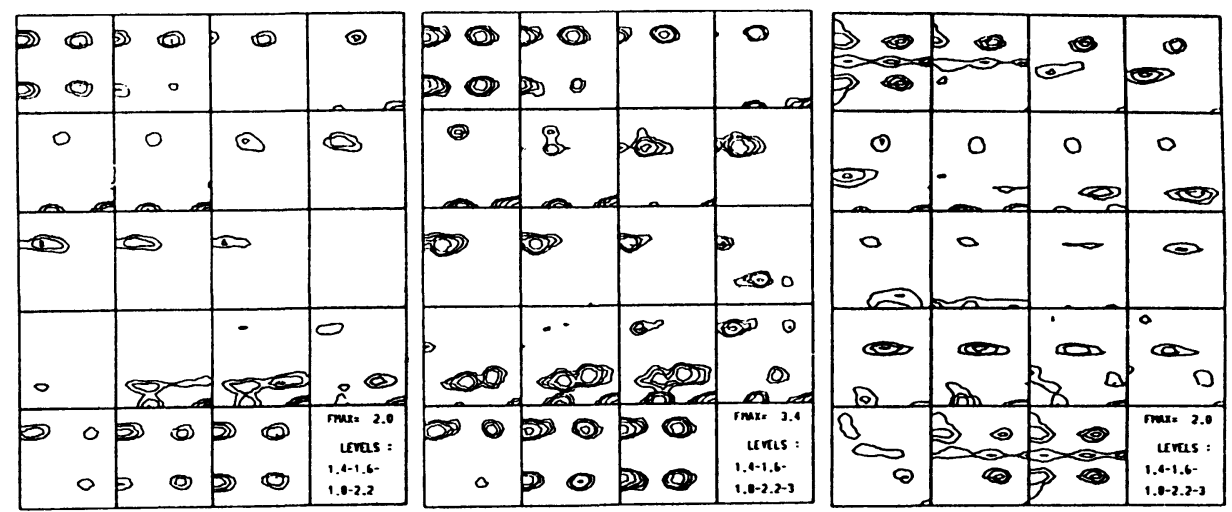

Fig.10 Compl. ODF for IC15 (a) cold rolled to 92\%, annealed for 1 h at $750^{\circ} \mathrm{C}$; (b) cold rolled to $90 \%$, annealed for $90 \mathrm{~min}$ at $710^{\circ} \mathrm{C}$; (c) exp. ODF for IC50, cold rolled to $92 \%$, annealed for $90 \mathrm{~min}$ at $850^{\circ} \mathrm{C}\left(\varphi_{2}=\right.$ const $)$

is in common with IC15, the $\{112\}<131>$ is much less pronounced, and there is an additional component $\{123\}<634>$ which is known as the $R$-orientation in recrystallization textures of rold fcc material. It is close to the S-orientation and may be a retained rolling component although the specimen is completely recrystallized.

\section{DISCUSSION}

The major difference in recrystallization kinetics between single phase IC15 and two phase IC50 is the sof tening prior to recrystallization and the temperature independent hardness subsequent to recrystallization of IC50. It is hard to see why IC50 should undergo recovery while the single phase does not, even with keeping in mind that the composition of the $\gamma$ ' phase is also different in both alloys. We surmise, however, that the sof tening may rather be due to an increasing precipitation of disordered $\gamma$ with increasing temperature which is sof ter than the ordered $\gamma^{\prime}$ phase, so that the total hardness will decrease. The continued hardness decrease of IC15 at elevated temperatures is known to be due to grain growth and the strong grain size dependence of the strength of $\gamma^{\prime}{ }^{1}$. The lack of hardness change in IC50 after recrystallization is then most likely due to the retardation of grain growth by $\gamma$ precipitates ${ }^{2}$.

The common recrystallization texture for different rolling textures of the two grades IC15 seems surprising at first glance. From the very unsymmetric pole figures of the coarse grained material ${ }^{1}$ it is evident, that the texture is not characteristic for the entire specimen but for a few large grains only. While the brass texture was also reported in a previous investigation of coarse grained $\mathrm{IC} 15^{1}$ is seems not to be identical but related to the large grain size and the respective deformation mechanisms. The very similar recrystallization textures indicate that the recrystallization mechanisms 
may be related to the common component, namely B. However, the recrystallization textures are very weak and the recrystallized grain size is very small, so that no strongly preferred nucleation or growth process can be convincingly accounted for the observed recrystallization textures. It is not unlikely that the heavy shear banding leads to preferential nucleation of the recrystallized grains in shear bands without major growth competition owing to the low mobility of grain boundaries in IC15.

The situation in IC50 seems to be similar as in fine grained IC15 except for the emergence of another recrystallization orientation. This orientation, however, is similar to the $\mathrm{S}$-orientation which is a major rolling texture component. Its occurrence is probably due to recrystallization in-situ because of the presence of $\gamma$ precipitates which will impede grain boundary motion, as known from other two phase materials.

\section{CONCLUSIONS}

(1) The microstructure and texture devleopment of two ductile intermetallic compounds, namely single phase (IC15) and two phase (IC50) $\mathrm{Ni}_{3} \mathrm{Al}$ was investigated during cold rolling and annealing.

(2) In the process of cold rolling a copper-type texture develops in IC50 and in fine grained IC15, but a brass-type texture in coarse grained IC15. The rolling texture develops rapidly but remains weak compared to disordered materials. The microstructural evolution is characterized by heavy shear banding, which is even more pronounced in coarse grained material.

(3) The recrystallization textures are even weaker than the rolling textures. Recrystallization textures in IC15 consist of two components on top of a very strong random distribution, which are different from recrystallization orientations found in disordered alloys. The additional component found in two phase material is attributed to in-situ recrystallization.

(4) The softening behavior on annealing of the single and two phase material is distinctly different. This difference is attributed to progressing precipitation during annealing of the two-phase alloy at increasing temperatures.

\section{REFERENCES}

1 G. Gottstein, P. Nagpal, and W. Kim, Mat. Sci. and Eng. A108, 165 (1989)

2 B. Zeumer, Diplomarbeit, RWTH Aachen (1990) 